\title{
Population Pharmacokinetic Modeling Of Flurbiprofen, The Active Metabolite Of Flurbiprofen Axetil, In Chinese Patients With Postoperative Pain [Expression Of Concern]
}

\begin{abstract}
Zhang J, Zhang H, Zhao L, Gu J, Feng Y, An H. Population pharmacokinetic modeling of flurbiprofen, the active metabolite of flurbiprofen axetil, in Chinese patients with postoperative pain. J Pain Res. 2018;11:3061-3070.

The Editor-in-Chief and Publisher of the Journal of Pain Research wish to issue an Expression of concern for the published article.
\end{abstract}

A reader raised concerns to the Editor about the validity of the data presented in the published article. It was alleged three authors of the present article, Zhang H, Feng Y and Gu J, had previously published the results of the study in the article:

Zhang H, Feng Y, Gu J. Distribution of flurbiprofen axetil in cerebral-spinal fluid after intravenous administration. Chin J Anaesthesiol. 2011;31(04): 432-434 doi:10.3760/ cma.j.issn.0254-1416.2011.04.012.

It was also alleged the clinical trial registration (CTR) number (ChiCTR-TRC-11001791) provided in the published article was taken from an unrelated study and had no association with the current study.

Upon review, a number of discrepancies were found between the study described in the article and the details provided for the registered clinical trial, ChiCTR-TRC-11001791 (www. chictr.org.cn/hvshowproject.aspx?id=1867). For example, the CTR number had been wrongly ascribed in the methods section of the published article as an ethics approval number for the Medical Ethics Committee of Peking University People's Hospital. The participants described in the published article ranged from 18-72 years of age, whereas the participants described in the registered clinical trial ranged from 60-120 years of age. The study outlined in the clinical trial was described as investigating cognitive dysfunction in elderly patients, however the present study was clearly described as investigating postoperative pain in patients as young as 18 years old. There were also 100 participants described in the registered clinical trial study (50 in each intervention group), while only 72 participants were described in the present article and none were ascribed to any specific intervention group.

Two Journal of Pain Research editorial board members were asked to review the article published in the Chinese Journal of Anaesthesiology and the present article. While they acknowledged similarities between them, they were unable to conclude with certainty that the data contained in both articles were from the same study. The authors and their institution, the People's Hospital of Peking University, were contacted and asked for an explanation and to provide the raw data for their study but no response was received.

As we were unable to reach a conclusive decision, the Editor-in-Chief would like to alert readers to these issues and allow them to reach their own conclusions.

Our decision-making was informed by our policy on publishing ethics and integrity and the COPE guidelines.

\section{Publish your work in this journal}

The Journal of Pain Research is an international, peer reviewed, open access, online journal that welcomes laboratory and clinical findings in the fields of pain research and the prevention and management of pain. Original research, reviews, symposium reports, hypothesis formation and commentaries are all considered for publication. The manuscript management system is completely online and includes a very quick and fair peer-review system, which is all easy to use. Visit http:// www.dovepress.com/testimonials.php to read real quotes from published authors. 